\title{
Effect of the National Health Insurance Scheme on Community-Based Health Planning and Services in the Vieri Zone of Wa West District of Ghana
}

\author{
Kanlisi Kaba Simon', Issaka Abdul-Hakim², Faustina Akwetey ${ }^{2}$ \\ ${ }^{1}$ Department of Governance and Development Management, Faculty of Planning and Land Management, University for Development \\ Studies, Wa Campus, Ghana \\ ${ }^{2}$ Department of Planning and Land Management, Faculty of Planning and Land Management, University for Development Studies, Wa \\ Campus, Ghana
}

\author{
Email address: \\ skanlisi@uds.edu.gh (K. K. Simon)
}

\section{To cite this article:}

Kanlisi Kaba Simon, Issaka Abdul-Hakim, Faustina Akwetey. Effect of the National Health Insurance Scheme on Community-Based Health Planning and Services in the Vieri Zone of Wa West District of Ghana. Humanities and Social Sciences. Vol. 5, No. 1, 2017, pp. 31-45. doi: 10.11648/j.hss.20170501.16

Received: January 23, 2017; Accepted: February 9, 2017; Published: March 4, 2017

\begin{abstract}
Ghana launched the Community-based Health Planning and Services (CHPS) initiative in the year 2000 in furtherance of the ideals of primary health care. The CHPS strategy was adopted by the MOH as a national programme to bridge the gap in access to healthcare. It provides for a Community Health Officer (CHO) to be resident in a community and with the help and support of the community members, to render some basic packages of PHC especially preventive services including home visiting, educational programmes and other health promotion activities and not sedentary clinical services at the health facility. With the introduction of the National Health Insurance Scheme (NHIS), which is a form of Health care financing in order to serve as a conduit for providing financial access to health care. This has perceptively resulted in an increase in out-patient attendance at all facilities especially CHPS facilities. This tended to constrain the CHOs from embarking on their mandated task of home visitation, educational programmes and other health promotion packages. It is against this background that this research work has been carried out to ascertain why the focus of CHPS is shifting from a preventive to a curative approach. The methodology adopted was a case study using a before and after approach to make comparison of the preventive health care activities of the CHO before and after the introduction of NHIS as well as access of people to the Vieri CHPS compound. Simple random sampling was used to select 165 households who were interviewed. We purposively sampled CHOs, the Community Health Management Committee (CHMC) and Community Health Volunteers (CHVs) who have in-depth knowledge on the operations of the CHPs. The study revealed that the frequency of household visitation and the educational programmes organized by the CHOs have declined. This is due to the net effect of NHIS on the facility and the CHOs due to increased attendance at the facility. This did not only negatively affect the activities that the CHOs are supposed to carrying out but also on the health infrastructure. The study also revealed various challenges faced by CHMCs and CHVs.
\end{abstract}

Keywords: Health, Care, Effects, National, Health, Insurance, Scheme, Community-Based, Health Planning Services

\section{Background}

Primary Health Care (PHC) is essential health care based on practical, scientifically sound and socially acceptable methods and technology, made universally accessible to individuals and families in the community through their full participation and at a cost that the community and the country can afford to maintain at every stage of their development in the spirit of self-reliance and selfdetermination (WHO, UNICEF 1978). The concept of public health is focused on helping people to stay healthy and protecting them from threats to their lives. It is the choice of every government to make healthier choices no matter the country's circumstance. Thus, from the advanced 
industrialized countries to the Least Developed Countries (LDCs), public health is a top priority in order to reduce the risk of illness in the entire population. The aim of public health is to enhance the quality of life of people through the identification, prevention and treatment of disease and other poor health conditions.

The concept of PHC was proposed at Alma Ata in 1978 and it explicitly emphasised the need for a comprehensive health strategy that not only provided for health services but also addressed the underlying social, economic and political causes of poor health (Tarino, et al, 1994, in Apetorgbor, 2008). The WHO in 1978 introduced the PHC concept as a shift from the hospital based system of health care to a community-based approach of health care. It adopts a more preventive approach to health care than a curative approach. It looks at maintaining the scientific method of health care, yet, ensuring that health care is socially acceptable and affordable to the beneficiaries of the health care. Major PHC activities include health promotion, prevention and control of locally endemic diseases, promotion of food supply and adequate nutrition, safe water and basic sanitation, maternal and child health care including family planning, immunization, appropriate treatment of common diseases and injuries, and provision of essential drugs.

In Africa, Ethiopia has a Health Extension Programme (HEP) which is one of the community-based health programmes that is similar to Community-based Health Planning and Services (CHPS) in Ghana. The Ethiopian strategy is designed to make healthcare geographically accessible to people in rural areas. It is a defined package of basic promotion, prevention and a selected high impact curative service targeting households. The programme is based on the basic principles and concepts of PHC. It is designed to improve the health status of families, with their full participation using local technologies and communities' skills and wisdom (HEP Profile, 2007, in Apetorgbor, 2008).

Ghana has adopted the Primary Health Care concept, and this is indicated in the Ministry of Health (MOH) public health care policy in 1978 which states that, most disease problems that cause the high rates of illness and deaths among Ghanaians are preventable or curable if diagnosed promptly by simple basic and primary health care procedures (Health Policies for Ghana, NHPU, 1977, cited in CHPS policy Document, 2005). The rational of this concept is to provide preventive services, and also bring health care close to the door steps of the people. Therefore extending the basic package of PHC services to all Ghanaians has been the key focus of the Ministry of Health since the Alma Ata conference on Health for All in 1978. Ghana's response towards attaining health care for all resulted in the Community-Based Health Planning and Services (CHPS) initiative. CHPS is a strategy adopted by the $\mathrm{MOH}$ as a national programme to bridge the gap in access to healthcare. The whole concept about CHPS began with the launch of the Navrongo Community Health and Family Planning Project (CHFP) in 1993 as a pilot project to determine the appropriateness of community based health planning and services. The result of the Navrongo experiment was replicated in Nkwanta which subsequently led to its actual national launch in 2000. There are a total of 1884 CHPS zones in Ghana (MOH, 2012).

Upper West region began CHPS in 2000 in Wa and Nadowli in 2004. The region, at the time had 10 fully functional CHPS zones with 6 in Nadowli and Wa. Upper West region through a collaboration between GHS and its development partners had a plan to establish 197 CHPS zones by 2015 (CHPS Review Report, 2009; CHPS Lead Districts' Readiness Assessment, 2002). Some of the key development partners are the Japan International Cooperation Agency (JICA) and PLAN Ghana. The number of CHPS zones has increased from 24 in 2006 to 81 in 2009 representing $41.1 \%$ and 84 in 2010. JICA has a current plan to construct additional 71 number CHPS compounds, between 2013 and 2015 (Nang-Benfubah, 2010).

CHPS provided an avenue for physical access to health care services, however the financial access was not taken care of since patients are expected to pay for the treatment of minor illness, and this is where Health Insurance comes in.

Health insurance is a form of healthcare financing. Health care financing is the process of ensuring that adequate financial resources are made available in order to provide sufficient access to needed health services for all residents (WHO, 2008). Health care financing comes in various forms including a direct payment system, prepayment health care financing system, tax-funded system and health insurance system.

The provision of health care in Ghana after independence was primarily free at all public health facilities. This means that, tax revenue was the only means of financing health care in Ghana. However, the sustainability of this became a challenging issue when the economy began to show signs of decline in the 1970s. This continued until 1985 when the Government was compelled under International Monetary Fund (IMF) and its Structural Adjustment Programme (SAP) pre-conditions to introduce user fees for all medical conditions except for certain specified communicable diseases and selected vulnerable groups such as the underfives, elderly and antenatal services for pregnant women. This led to the creation of financial barriers towards access to health care, especially for the poor and needy, which resulted in delays in seeking health care, non-compliance to treatment regimes and consequently premature deaths.

The National Health Insurance System was therefore introduced to serve as a conduit for providing financial access to health care. It was established by the National Health Insurance Act (Act 650) in 2003 and lunched in 2004 by the Government of Ghana (MOH 2004, Government of Ghana, 2003). This was basically a response to the adverse equity impact of the out-of-pocket payment system- 'Cash and Carry'. It had a goal of providing equitable and universal access to health care in Ghana. The Act provided for the operation of three types of health insurance schemes in the 
country, namely, the District Mutual Health Insurance Schemes (DMHIS), Private Commercial Health Insurance Schemes (PCHIS), and Private Mutual Health Insurance Schemes (PMHIS). The National Health Insurance Scheme (NHIS) was introduced in the Upper West Region of Ghana in October 2004.

\subsection{The Research Problem}

About 8.6 million Ghanaians are hooked to the NHIS. There is no doubt that this coverage will ensure an almost free access to healthcare for households especially those in rural neighbourhoods. The focus of CHPS is to provide health services at the door steps of the people through home visiting and health education. The focus of the National Health Insurance is to ensure equity in financial access to health care. Health insurance provides a reliable source of finance for the management of the CHPS facilities hence becomes a reliable alternative to manage outpatient cases at the facility than the home visit and its associated stress hence it is perceived that it has a negative impact of crowding health facilities day-in day-out. This has perceptively resulted in an increase in out-patient attendance at all facilities especially our CHPS facilities which should provide preventive health care via Community Health Officials (CHOs).

Previous studies on CHPS focused on its achievements in reducing infant and maternal mortality and its implementation processes. Other studies dwelled on the impact of the CHPS on the rural folk; and the impact of the Health Insurance on the populace. Results revealed wellproven records of reduction in maternal mortality and underfive mortality by $16 \%$ (Pence, et al., 2005, cited in Apetorgbor, 2008) but the net effect of NHIS on the CHPS practice is still unknown.

Therefore, in spite of the fact that the NHIS is serving as a conduit for health care financing in Ghana, how it is shaping the CHPS practice in rural Ghanaian communities from the delivery of more preventive initiatives to a more curative approach is not known. It is on this premise that this research was carried out to investigate the consequences of the NHIS on the CHPS practice.

\subsection{Research Questions}

Generally, the study sought to answer the following questions:

How has NHIS affected the CHPS concept in the Vieri CHPS zone?

Specifically, the study addressed the following questions:

a) Why is the focus of CHPS shifting from a more preventive approach to a curative approach in Vieri CHPS zone?

b) What is the accessibility trend of people to the Vieri CHPS compound?

c) What is the effect of the accessibility trend on the facility in the Vieri CHPS compound and the services delivered?

\subsection{Methodological Perspective}

Generally, this study was conducted using a before and after approach, while the Vieri CHPS zone was the focal case for analyses. This approach enabled the researchers to conduct holistic analyses of the practicality of the CHPS concept.

Both primary and secondary data were collected. Primary data was collected at the household level which was the basic unit of analysis as well as data from the CHPS compound such as O. P. D attendance records. Extensive literature from the Regional and District Health Directorate and the District Health Insurance Authority; reports of Government of Ghana, MDG Reports of Ghana, reports of the Ghana Health Service and Ministry of Health, publications including journal articles and books were also reviewed.

The communities within the Vieri CHPS zone included the following: Vieri, Lomwama and Gorziri.

Table 1. Various communities and number of households within the CHPS zone.

\begin{tabular}{lllll}
\hline Communities & Population & $\begin{array}{l}\text { Percentage of } \\
\text { population }\end{array}$ & $\begin{array}{l}\text { Number of } \\
\text { households }\end{array}$ & $\begin{array}{l}\text { Percentage of } \\
\text { household }\end{array}$ \\
\hline Vieri, & 1410 & 80 & 231 & 82 \\
Lomwama, & 89 & 5 & 11 & 4 \\
Gorziri & 264 & 15 & 40 & 14 \\
Total & 1763 & 100 & 282 & 100 \\
\hline
\end{tabular}

Source: Vieri CHPS compound 2016.

A sample size of 165 out of 282 households was selected at $95 \%$ confidence level. Each community was allotted a quota of the sample size that reflected its percentage of total households served by the Vieri CHPS compound. Therefore, the number of respondent households in Vieri was 135, Lomwama was 7, and Gorziri was 23.

To also ensure reliability and fair representation of data, systematic sampling technique was used, thus every third house was selected.

Purposive sampling which is non-probability sampling technique was also used to solicit information from participants with special knowledge about CHPS practice such as the CHOs, the CHV and the CHMCs.

Methods used in collecting primary data included questionnaire administration at the household level, direct observation at the Health Facility level and key informant interviews to solicit opinions of community opinion leaders and health officials due to their in-depth knowledge.

\section{The Study Area}

The Vieri CHPS Zone is situated in the Wa West district of the Upper West Region of Ghana. The Wa-West district is located in the western part of the Upper West Region approximately between Longitudes $9^{\circ} 40^{\prime} \mathrm{N}$ and $10^{\circ} 10^{\prime} \mathrm{N}$ and also between latitudes $2^{\circ} 20 \mathrm{~W}$ and $2^{\circ} 50^{\prime} \mathrm{W}$ (see figure 1 ). The Vieri community is about $36 \mathrm{~km}$ from the district capital Wechiau. It is bounded to the North Eastern part by Lomwana, North Western part by Gorziri, to the East by 
Pigbengbe and to the south by Wolloyiri. The settlement pattern is nucleated within the central part of the community and dispersed at the community's extreme ends.

The total population of the Vieri CHPS zone is 1763, with Vieri, Lomwana and Gorziri having 1410, 89 and 264 respectively. The total number of males is 855 and females being 908. The natives of the Vieri zone are predominantly Dagabas, followed by Walas. They practice different faiths with Christianity being the dominant, Islam being the second and Africa Traditional Religion (ATR) being the least.

\section{Conceptual and Theoretical Perspectives}

\subsection{Health}

The concept of health is elusive and ambiguous depending on the professional orientation of the person defining it. Though commonly used from day to day in different walks of life, it is interpreted differently by different people. The concept of health has evolved with the passage of time from a narrow definition and more negative to a more positive and broader one.

Conventional definitions of health were concerned basically with the mechanical functioning of the human body parts and presented health as the absence of disease. It has also be noted that one is well if he is able to carry on his usual daily activities. To the extent that he is not, he is in a state of deviation from well-being. He presents his definition in a negative way, focusing on just the ability to carry out a person's daily routine in a consecutive manner ignoring other determinants as social network with people. This presumes the body to be a system made up of several interdependent parts. This goes further to imply that malfunctioning of one part of the human body renders the whole body dysfunctional. This point to the fact that, health was viewed purely as a biomedical concept, having to do with disease infestation, physiological difficulties and organic deficiencies and while germs and genetics were deemed as causes of ill health. It also implies that the approach to health then was curative and clinical.

Positive definitions of health include both negative (absence of disease) and positive elements. Such definitions include that of the Nottingham Health Authority (NHA, 1990), which explained the concept to be an equilibrium or a balanced state in which the individual is not restricted by physical or mental impairment from participating as fully as they would want in all that their environment has to offer, or from bringing about environmental change. This definition implies a balance between an individual and his environment. Thus, an individual's ability to challenge his environment and be in a stable state and take part in all happenings around him. It implies the absence of physical and mental obstacles that prevents a person from partaking in the events of the society he/she belongs.

The World Health Organization (WHO, 1978) indicated health as a complete state of physical, social and mental wellbeing and not merely the absence of disease or infirmity. This definition is multi-dimensional in emphasises as it implies both medical and non-medical aspects of health (social, psychological and physical). Under it, health is viewed holistically focusing on public health, biomedical health and socio economic conditions that determine health. It is based on the fact that every individual belongs to a household, a family, a community and society- and therefore his lifestyle and health is dependent on the rest of the society and also has consequences on the society. It further implies that an individual's state of health cannot be the responsibility of only the doctor or the physician alone but also depends on the individual as well as other professionals and society as a whole to make each and every one healthy. Going forward, it can be inferred that health is a state of a person's being which is defined various factors including the state of society itself, the environment, the personality involved and the general systems that evolved to provide care for the people.

\subsection{Determinants of Health}

Over the years, determinants of health such as environmental, political, cultural and socio-economic determinants have become central in understanding the causes of ill health. Factors such as safe water and clean air, healthy workplaces, safe houses, clean communities and roads, clean technologies, healthy diet among a host of others determine the state of well-being of an individual as there is a co-dependence between the individual and these environmental factors. Factors such as education, employment, food, peace and security, shelter, social relationships, support networks all come into determining an individual's health as they affect him/her in one way or the other. The way of life of a group that an individual belongs to, determine his state of health. Customs and traditions, belief systems, values and norms may affect the health of an individual. - For example, the Trokosi system, Female Genital Mutilation, widowhood rites, witchcraft and some rites of passage, perception of 'spirit children' may affect a person physically or psychologically and render him or her unhealthy. The decisions of political heads and political agendas as well as the types of regimes in place tend to determine the state of health of the citizenry of a country. The psychological perception of a person may also cause $\mathrm{him} / \mathrm{her}$ to experience ill-health, when in actual fact the elements perceived are not real.

\subsection{Health Care System}

Health care has been described as the conduit through which societies provide the needed support for citizens to maintain them in a desirable state. This includes all services provided by health professionals and other related staff focusing mainly on preventing, curing and managing illness as well as preserving a state of physical and mental wellbeing for people. From a biomedical perspective, health care is provided by only trained health professionals. However, 
health care is not given only at the time when one is ill but include the care given at various stages before, during and after illness. The health system that prevails in a given society at any point in time is an integration of several dependent and independent variables including service delivery, health personnel, health data sets, medical products, health equipment and technology, financing and health governance.

\subsection{Curative Health Care}

It is the type of medical treatment and care that cures a disease or relieves pain from a disease or ill health and promotes recovery (WHO, 2004). Curative health is health care focused on treating or giving medication for relieve from illness or a disease. This means that curative health is solely concerned with direct contact between a physician and a patient. It is mainly about diagnosing patients in clinical facilities and prescribing medications and giving other directives to lessen their ill health. Also, it is simply the health care that is provided to a person when he/she is ill or is infected with a disease. Curative health care ranges from a whole lot of processes from diagnosing to prescription of drugs to keep the person back to a state of normal health. This type of health care could be described as a reactive approach to health care since it waits for sickness to occur in order to cure them.

\subsection{Preventive Health Care}

It is the type of care that has the aim of preventing disease or its consequences which includes health care programmes aimed at warding off illnesses, early detection of disease, and inhibiting further deterioration of the body (WHO, 2004). Preventive care focuses on an ensemble of measures taken to prevent disease rather than treating them thus, measures taken to avoid the occurrence of diseases or illness. Preventive health care commits resources to prevent the occurrence of diseases. There is a current shift by most governments from merely curing diseases to preventing them as this may save government's limited resources. This is because it ensures that cost effective strategies are adopted to prevent illness in order to have a healthy population rather than committing huge sums in the purchase of drugs to cure illness. Preventive health could be said to be a proactive approach to health care since it prevents diseases in advance rather than waiting to cure illness of patients.

\subsection{The Concept of Community-Based Health Planning and Service (CHPS)}

Community-based Health Planning and Services is "the mobilization of community leadership, decision making systems and resources in a defined catchment area (zone), the placement of re-oriented frontline health staff known as Community Health Officer (CHO), with logistics support in community volunteer systems to provide services according to the principles of Primary Health Care (PHC-Plus). It is a "close- to- client" service delivery system (GHS, 2005; pp.
7). The CHPS is the third (level A) of the three tiered health delivery hierarchy at the District level which provides health care at the door steps of community members with their participation.

\subsubsection{CHPS Zone}

The CHPS zone is the demarcated catchment area for the rendering of health service for a community, which may usually comprise of two to three unit committees within a sub-district. The CHPS Zone becomes fully functional when all the essential elements required to render the basic package of PHC are deployed to the zone (GHS, 2005).

\subsubsection{CHPS Compound}

A CHPS Compound is the facility provided for the delivery of the basic package of primary health care for community members within the CHPS zone. It serves as the medium for service delivery between the $\mathrm{CHO}$ and the community members aside outreaches of the CHOs. The facility could be provided by the community in part or whole, the local government or donor agencies.

\subsection{Theoretical Perspectives}

The communitarian theory is the basis for communitybased health initiatives since there is no specifically laid down ethical theory of community based health. The theory is however built on the pillars of communitarianism. This implies that the term community is central with regards to the concept of community based health. A community is basically a population or group defined by its common characteristics, experiences, its location or geographic origin; physical, behavioural, or personal characteristics, beliefs, values, interests, norms or goals.

Community health focuses on the health of identified groups in making decisions with the aim of promoting, protecting, and preserving the health of one or more defined populations (Heitman \& McKieran, 2003).

Communities play a vital role in ensuring community health because the health of an individual member of the community has implications for the rest of the community. The communitarian theory therefore posits that communities are more likely to pool resources to determine their own health, since they share a common destiny.

Communitarianism developed in the 1980s in response to a perceived rise in overemphasis on individual rights. Like community based health, communitarian theory holds that, individuals cannot be separated from their community's life, and that no one person or community can ever be completely self-sufficient as far as community life is concerned. This is because rural communities have a sense of togetherness and interdependence. They are closely knitted. Communitarian theory also states that, though individuals make their own moral choices, their moral commitments and values are shaped by the community's norms and experiences. Communitarian theory holds that one's choice focuses on the individual's direct benefit as well as the benefit that the individual enjoys as a member of a community (Heitman and 


\section{McKieran, 2003).}

Community based health is a grass-roots phenomenon linked with the involvement of health staff backed by individuals and the communities in which they live in order to promote and protect their own health. Community based health could be inferred as involving a defined population in protecting and promoting their health through planning, operating, financing, controlling and sustaining their health system. Community participation in health goes beyond mere participation and redistribution of power to include traditional authorities in information sharing, setting primacies, allocating resources and distributing benefits and services of the entire process. These communities are mostly those with limited knowledge, technical skills and access to power, hence their involvement leads to empowering them through building the capacity of some of their members to help in promoting their health since they know better the existing situation.

\subsection{Analytical Framework}

The National Health Insurance Scheme and the CHPS initiative are both results of the Alma Ata Declaration of 1948. This is in view of the fact that both elements are meant to ensure equitable access to health care both geographically and financially and between different groups (socioeconomically, politically and culturally). Both strategies ensure access to health care irrespective of the type of community (urban or rural), religion (Christianity, Islam or African Traditional Religion-ATR), and income status (rich or poor). Just as health insurance ensures financial access to health care, so does the CHPS ensure easy geographical access to health care by bringing the health service closer to the door steps of the community members.

With specific analysis of the CHPS system, it is in response to the principles of the Almata declaration and for that matter primary health care that it is in existence. It is to provide curative and preventive health in line with the basic principles of primary health care. Though the declaration did not specify the magnitude of health care delivery between preventive and curative health, the CHPS system in Ghana makes it more of preventive health and a little proportion of curative health. The preventive health care package of the CHPS system includes health education on environmental sanitation and personal hygiene, family planning services, promotion on nutrition, adequate supply of safe water, maternal and child care, immunization against the major infectious diseases, prevention and control of locally endemic diseases, education concerning prevailing health problems and the methods of preventing and controlling them etc. and a bit of curative health such as treatment of minor ailments such as malaria, sores and other minor injuries. Additionally, the CHPS system involves decision making such as identifying health needs of the community, planning and organizing the health system of the communities thus taking health decisions affecting their own lives. The CHPS also represent the first point of contact for health care for the communities as is the case with the principles of the PHC.
The core of the CHPS system is the home visiting and outreach services embarked by the $\mathrm{CHO}$, which all forms part of rendering the preventive health care package.

The health insurance Scheme came in to ensure that the financial barrier posing as a constraint to access health care is eliminated. This is done by prepayment against the risk of getting sick and in a way transferring the financial burden to the scheme. Since the prepayment is against the risk of getting ill, it implies that the health insurance scheme is purely a curative health initiative simply because of the above explanation of curative health as medical treatment and care that cures a disease or relieves pain from a disease or ill health. Moreover, since people in these communities are clients of the national health insurance scheme, it implies that they have a right of access to health care facilities that are signed service providers under the NHIS since health has been described by the WHO as a fundamental human right. Currently, all CHPS compounds are health insurance accredited which makes it easier for the people in these communities to access health care in the first facilities closest to them which is the CHPS compounds (level A). The CHPS facilities are compelled to render curative healthcare for the clients of the health insurance scheme since. The result here is the increase in the proportion of curative health care services to be rendered by CHPS at the expense of the preventive services. This is in view of the fact that consumers would like to maximize their satisfaction due to the value of their contribution (monies) and therefore would use it unnecessarily knowing that the cost will not be felt by them (moral hazard). With the analysis above, it is perceived that attendance at the NHIS accredited health facilities will increase with various implications for the curative health care packages, whiles the preventive health package reduces drastically. This is likely to turn the CHPS compounds into clinics as their focus is diverted. The analysis above is presented in the framework illustrated below.

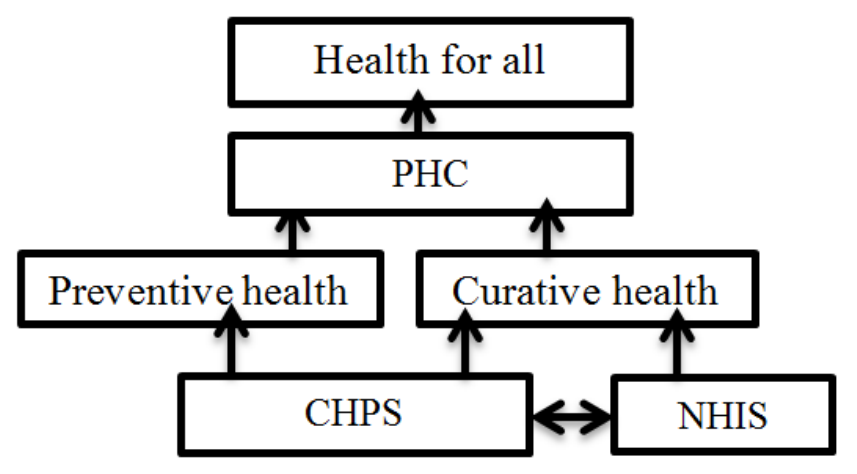

Source: Authors' construct 2016.

Figure 1. Analytical framework for net effect of NHIS on CHPS.

The framework above simply explains the linkage of both CHPS and NHIS towards the attainment of PHC and the ultimate goal of the Alma Ata Declaration of "health for all". In the above diagram, CHPS provides a double package of both preventive and curative health towards the attainment of PHC and the goal with the former been dominant. NHIS 
promotes access to just curative health, which implies that the package of curative health to be provided by CHPS will increase as is depicted by the double arrow pointing from both NHIS and CHPS towards curative health. This is simply justified by the view that, curative health will have a single arrow from CHPS in the absence of health insurance. The two way directional arrow also shows the interdependence between the two systems as CHPS serves as a conduit through which clients of the NHIS access their curative health care and CHPS as well relying to some extent on the revenue from NHIS to sustain it.

\section{Results}

\subsection{Demographic Characteristics of Interviewees}

The researchers interviewed a total of 165 households in the Vieri CHPS zone with three communities falling within its catchment area thus, Vieri, Gorziri and Lomwana.

Out of the total of 165 interviewees, 93 respondents were males and 72 were females. For the respective communities however, there were 80 males and 55 females for Vieri, 7 males and 16 females for Gorziri and 6 males, 1 female for Lomwana. Generally, there were $56.4 \%$ male respondents and $43.6 \%$ female respondents. This is illustrated in the table below.

Table 2. Sex of respondents by communities.

\begin{tabular}{|c|c|c|c|c|c|}
\hline \multirow{2}{*}{ Community } & \multicolumn{4}{|c|}{ Number of respondents by sex } & \multirow{2}{*}{ Total } \\
\hline & Male & $\%$ & Female & $\%$ & \\
\hline Vieri & 80 & 59.3 & 55 & 40.7 & 135 \\
\hline Gorziri & 7 & 30.4 & 16 & 69.6 & 23 \\
\hline Lomwana & 6 & 85.7 & 1 & 14.3 & 7 \\
\hline Total & 93 & 56.4 & 72 & 43.6 & 165 \\
\hline
\end{tabular}

Source: Authors' construct 2016.

\subsection{CHPS and the PHC Package}

The CHPS initiative is an essential strategy to bring the essential packages of PHC to the door steps of community members through the frontline health officer, the $\mathrm{CHO}$ by involving the community members. This is in recognition of the fact that individuals and households are the essential producers of health care. In fulfilment of this mandate, it is structured to provide more of preventive health care and education through effective participation of communities in planning and communicating its activities. The basic packages of $\mathrm{PHC}$ to be provided by the $\mathrm{CHO}$ include embarking on outreach programmes within their catchment areas known as zones, public education on personal hygiene and other sanitary related issues. They are also required by the policy to embark on home visits and provision of limited curative health care such as provision of essential drugs and first aid treatment of minor ailments that do not require any referral. Originally, the basic packages of CHPS includes: health promotion and prevention, management of common ailments and their referrals and, case detection mobilization and referrals. This package is realized through outreach programmes, home visiting and health education and campaigns at the community level.

In light of this mandate, the CHOs in the Vieri CHPS zone embarks on home visitation, outreach programmes to Gorziri and Lomwana and organizing health educational programmes for the entire communities. Out of the 165 households who were interviewed, $96.4 \%$ of them indicated that the CHOs were responsive to their duties before the introduction of the National Health Insurance Scheme than after its introduction $(85.5 \%)$ as illustrated in figure 2 .

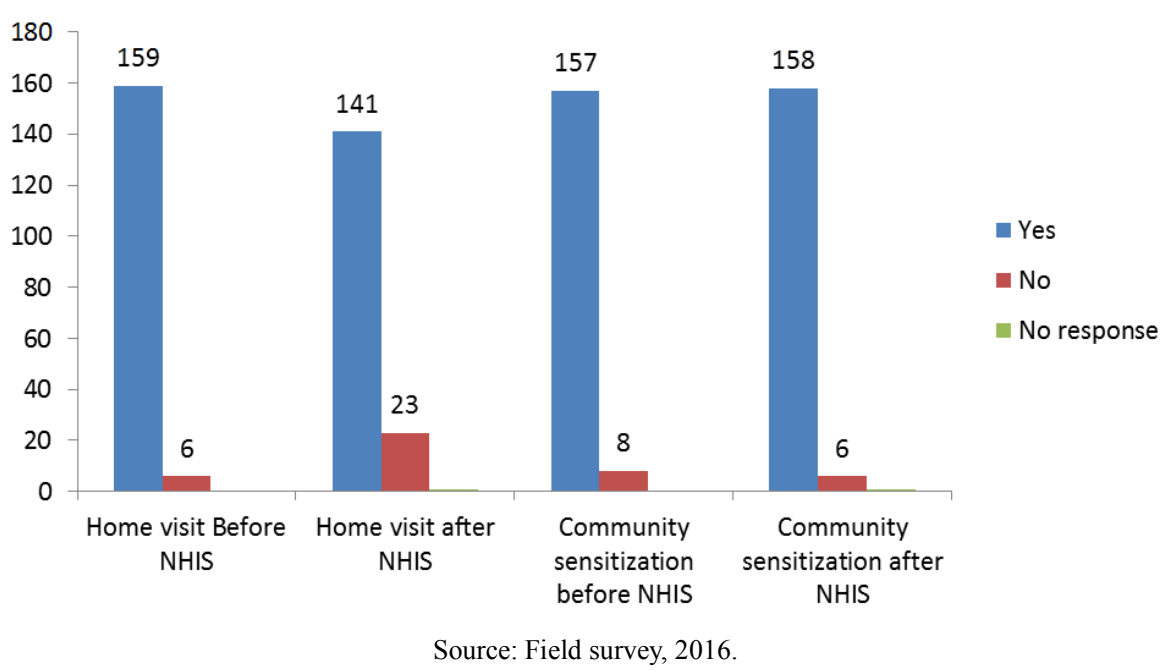

Figure 2. Responses on home visiting and community sensitization.

The services provided through these activities according to the households included education on personal hygiene, environmental hygiene and other health promotion activities. Some of them include bathing of children and brushing their teeth early in the morning, giving children hot food, teaching parents how to prepare good and nutritious food for their wards, advising parents to take good care of their children (most especially those five years and below) and bring them 
to the CHPS compound whenever they are sick. The latter is in view of the attempt by the $\mathrm{MOH}$ and the GHS to reduce neonatal and infant deaths in order to attain the Millennium Development Goal on infant mortality. Other services provided through home visitation included effective washing of cooking utensils, sweeping compounds and weeding bushy surroundings, sleeping under long lasting insecticide treated nets (LLITNs) to prevent malaria, subscribing to the NHIS as well as family planning services. Services that the CHOs provided through community sensitization included HIV/AIDS prevention, malaria prevention, avoiding teenage pregnancies, avoiding crowding in rooms to prevent easy transfer of communicable diseases, effective preparation of nutritious diet, organizing clean up campaigns and organizing durbar for the community to deliberate on health issues and pool resources to strengthen the community health system. Other programmes were also organized for specific groups such as women to educate them on child care and family planning issues. Youth groups were also educated on preventing HIV/AIDS and teenage pregnancies by practicing safe sex.

In line with the preventive health care services, the activity line up of the CHPS zone are indicated in table 3.

Table 3. Health promotion activities of the Vieri CHPS zone.

\begin{tabular}{ll}
\hline Month & Activity \\
\hline January & Benefits of exclusive breast feeding \\
February & HIV/AIDS, PMTCT/VCT \\
March & Malaria/CSM/Guinea worm sensitization \\
April & Personal/Environmental hygiene \\
May & Importance of ANC/PNC/CWC \\
June & Benefits of skilled delivery \\
July & Danger signs in pregnancy \\
August & Benefits of family planning \\
September & Talk on Tuberculosis (TB) \\
October & Preparation of balanced diet \\
November & Creating awareness on Hepatitis B\&C \\
December & Prevention of childhood diseases \\
\hline
\end{tabular}

Source: Vieri CHPS compound, 2016.
Even though these activities were planned, household respondents concluded that they were not satisfied with the regularity in which the activities were carried out after the NHIS was initiated as compared to what used to be the case before.

\subsection{Interval of the Activities for the CHPS Zone}

Responses from the three communities within the CHPS zone revealed that the CHOs embark on such activities weekly, fortnight, monthly and others including every two months, every 3 months, every four months, and every six months. However, generally, the frequency of home visitation activities reduced drastically after the introduction of the NHIS.

Similarly, the regularity of community sensitization activities also reduced. Weekly, fortnightly and monthly visitations for example all reduced according to household respondents

Responses indicating that the CHOs embark on home visiting weekly before the introduction of NHIS are dominant as 81 households representing $51.5 \%$ agree to this followed by monthly, $46(27.9 \%)$. Also with home visiting after the introduction of NHIS, monthly is the highest with 60 households $(36.4 \%)$ followed by fortnight with 41 households $(24.8 \%)$. With the organization of community sensitization programmes before the introduction of NHIS also, majority of households thus 90 representing $54.5 \%$ say it is organized monthly before the introduction of NHIS. Household responses also show that after the introduction of NHIS, sensitization programmes were still organized monthly as 110 households responded to 'monthly' thus representing $66.7 \%$. From the above, it could be deduced that, before the introduction of NHIS, home visits were carried out in periods ranging between one week to every month and now after the introduction of NHIS between every two weeks to one month (see figure 3 ).

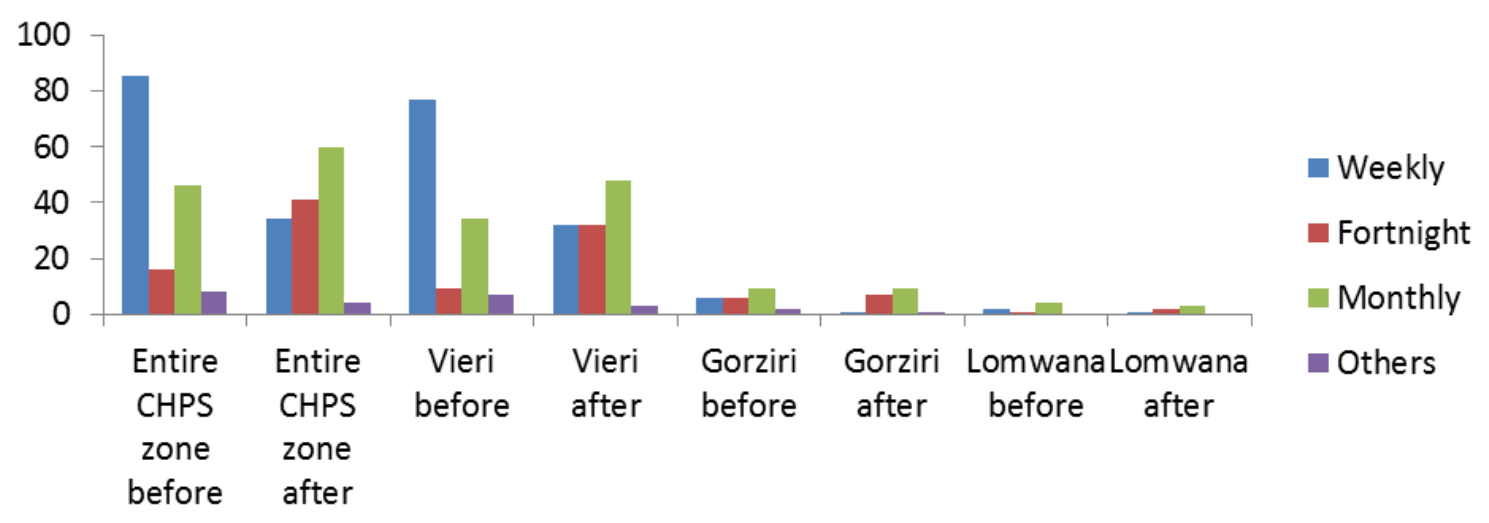

Figure 3. Home visits before and after the introduction of NHIS.

For the specific communities also and in Vieri which has the largest population, 77 households $(57 \%)$ concluded that home visiting was carried out weekly but now with the introduction of NHIS it ranges between every two weeks to a month with $32(23.7 \%)$ households and 48 (35.6\%) households respectively. Sensitization programmes before the introduction of NHIS were also carried out monthly to every 2-3 months as it recorded 73 households (54.1\%) and 29 
households $(21.5 \%)$ respectively. After the introduction of NHIS, it is still carried out every month to every 2-3 months as 90 households $(66.7 \%)$ and $26(19.3 \%)$ respectively reveal this.

For Gorziri with the second largest population also, households indicate that home visiting before the introduction of NHIS was carried out mostly between two weeks and monthly basis as these recorded 9 households $(39.1 \%)$ and 6 households $(26.1 \%)$ respectively and the same periods after the introduction of NHIS as these still recorded 9 households (39.1\%) and 7 (30.4\%) Figure 4: Community sensitization programmes before and after the introduction of NHIS respectively. With the organization of community sensitization programmes also, both the interval before and after the introduction of NHIS still remained monthly with 12 (52.2\%) and $15(65.2 \%)$ households respectively.

For Lomwana community with the least population, home visiting was carried out monthly for both before and after the introduction of NHIS as households responding to monthly are $4(57.2 \%)$ and $3(42.9 \%)$ respectively. With the organization of community sensitization programmes before and after the introduction of NHIS, 5 (71.4\%) households responded that it takes place on monthly basis as it recorded 5 for both periods. Though there is variation in the periods, households reveal that the services provided for home visiting and community sensitization programmes both before and after the introduction of NHIS remained the same.

Some of the totals of the interval responses fall short of certain percentages making them less than $100 \%$. This is simply because respondents that say such activities (home visiting and community sensitization programmes) were not embarked on did not respond to the question on the intervals. For instance in the entire CHPS zone, six (6) households answered 'No' to home visiting and two (2) have no answers, giving a total of $8(4.8 \%)$. This deduction from $100 \%$ gives a total of $95.2 \%$

\subsection{CHO's Response on Their Roles as Mandated by the CHPS Policy}

The community health officer is the frontline health officer that helps in determining and promoting the health of community members in their catchment areas. The $\mathrm{CHO}$ plans health activities with the CHMC and volunteers selected by the Committee. CHOs as per the mandate of CHPS are to embark on home visits, immunization, and health promotion activities e.g. ANC, CWC, PNC, family planning, defaulter tracing, treatment of minor ailments, etc.

In response to this mandate, the statistics for the activities carried out in the CHPS zone are illustrated in the table 4.

Table 4. Statistics on home and household visits.

\begin{tabular}{lllll}
\hline $\mathbf{8}$ & Period (Months) & Number of homes visited & Monthly average & Number of Households visited \\
\hline 2007 & 9 & 308 & 34.2 & 277 \\
2008 & & & & \\
2009 & 9 & 437 & 48.6 & 551 \\
2010 & 12 & 918 & 76.5 & 1325 \\
2011 & 12 & 686 & 57.2 & 1059 \\
2012 & 10 & 537 & 53.7 & \\
2013 & 11 & 1093 & 99.4 & 1142 \\
\hline
\end{tabular}

Source: Vieri CHPS Compound, 2016.

In the table above, the essence is to do a before and after comparison of home visiting, outreach programmes and other health promotional activities in order to analyses the relationship between the two variables (NHIS and CHPS) in order to determine the former on the latter. However, due to lack of statistics stemming from poor record keeping, such data is not available for periods before the introduction of NHIS (2000 to 2004). This has constrained the researchers in carrying out such comparison.

However, the CHOs upon interviews express their thoughts between these two variables by explaining that NHIS has really changed the concept of CHPS. They further explain that it has made community members perceived the CHPS compound as a clinic. This has increased and is still increasing OPD attendance and as such limiting their ability to carry out their actual mandate by embarking on home visits and other preventive health activities. One of the nurses laments, "NHIS has actually affected the concept CHPS in the Vieri community because they now prefer curative to preventive. Hence increasing OPD attendance to the extent that, $\mathrm{CHO}$ cannot go out to carry out other activities".
Another CHO further explains that initially when NHIS was not introduced, they embark on their home visits early in the morning before coming to the compound to take care of other activities. However, with the introduction of NHIS, before she is to undertake her activities, patients are already at the facility to be attended to and for that matter cannot embark on it anymore.

Challenges faced by the CHOs included the following:

- The CHO has no motor bike to carry out her activities of home visiting and outreach programmes. The CHO has to walk a distance of $1.5 \mathrm{~km}$ to $2 \mathrm{~km}$ to reach her outreach points. The stress of walking coupled with other factors constrains her in carrying out these activities.

- There is no cold chain system at the facility to enable them to be able to store vaccines and certain drugs that need a cold system. They have to move to their Subdistrict capital to store these vaccines and bring them back when needed.

- Also there is no emergency system in the community that help to ease the work of CHOs in referring patients 
to the next level facility. They usually resort to the use of motorbikes which is very risky especially for pregnancy cases.

\subsection{Response of Community Health Volunteers (CHVs) to Their Roles}

Community health volunteers are the structures put in place to ensure the proper functioning of CHPS in the Vieri zone. They serve as a link between the $\mathrm{CHO}$ and the people they represent. The Vieri zone currently has ten volunteers, seven at Vieri, two at Gorziri and one at Lomwana. Out of the ten volunteers, six were interviewed thus three from Vieri, two from Gorziri and one from Lomwana.

\subsubsection{Roles of $\mathrm{CHVS}$}

Interviews held with $\mathrm{CHVs}$ revealed a number of roles they perform with regards to CHPS. To clearly identify the lapses in their roles performed, a comparison is made with CHPS policy roles the roles specified at the CHPS compound.

i. Policy Roles

- Provision of preventive and curative services for malaria and diarrhoea

- Provision of family planning counselling

- Referral of serious cases to CHOs and clinics

- Health education using "Road to Health Chart" etc.

- Identifying children lacking immunization and those failing to thrive

- Early notification of disease appearance to the $\mathrm{CHO}$

ii. CHPS compound specified roles

- Assist CHOs on community mobilization of health

- Link between CHOs and hard to reach areas

- Establishment and maintaining registers

- Assist in data collection

- Notification on preselected events that require immediate intervention

- Participate in information dissemination

- Social mobilization and problem identification

- Conduct emergency immunization

- Enhance community based surveillance through detection, notification and reporting of a single case as a border outbreak.

iii. Volunteers responses regarding their roles

- Information dissemination

- Assisting CHOs in organizing Child Welfare Clinic (CWC) and immunization

- Help in organizing health meetings

- Organizing clean up exercises to tidy up the CHPS compound

- Distribution of drugs and vaccines

- Checking on health of households

- Reporting cases detected and new births to CHOs

- Organizing the youth for clean-up exercises

- Holding meetings with CHOs to identify health problems

- Giving first aid to sick persons in case of emergency A comparison of the three categories of roles above clearly reveals that, the volunteers completely work in line with their mandatory roles. This implies that the volunteers are really beneficial to the health system of the community as far as CHPS is concerned. However, they are saddled with a few constraints in spite of these numerous roles which limit their ability to perform these tasks more effectively. These are outlined below.

\subsubsection{Constraints Faced by CHVs}

\section{a Logistical constraints}

All the six volunteers interviewed complain of lack of logistics to enable them carry out their task effectively. Such includes bicycles, torch lights, wellington boots, and rain coats. They lamented that bicycles which were distributed to them in 2005 to serve as their means of transport since they were selected as volunteers are all defunct. This limits their ability to reach their working destinations as they need to move by foot. Also, they complain that they do not have torch lights to help them at night when they are rushing a patient to the CHPS compound and wellington boots to wear due to the certain environmental hazards. As well, they lack rain coats to wear during the raining season to carry out their task but these are not the case.

b Lack of motivational and incentive packages

The policy makes it for volunteers to render their services free of charge to the communities which our research also reveals. The volunteers upon interviews express their displeasure at this happening since they had been working for not less than 10 years without motivational packages. They even have to incur extra cost which is from their own resources in order to attend meetings organized at their subdistrict capital (Lassie).

They further explain that they spend time out of their busy schedules with the CHOs and community members in attending to health issues at the expense of their farm and other works where they earn their livelihood to cater for their families but with no package to compensate the losses.

\subsubsection{CHVs Experience with the CHPS Practice Before and After the Introduction of NHIS}

CHVs also reveal their experience with the CHPS practice as specified in the table below.

Table 5. Response of CHVs to home visits and community sensitization.

\begin{tabular}{lllll}
\hline \multirow{2}{*}{ Interval } & \multicolumn{2}{l}{ Home visiting } & \multicolumn{2}{l}{ Community sensitization } \\
\cline { 2 - 5 } & Before & After & Before & After \\
\hline Weekly & 5 & 0 & 1 & 0 \\
Fortnight & 1 & 2 & 2 & 2 \\
Monthly & 0 & 4 & 3 & 4 \\
\hline
\end{tabular}

Source: Vieri CHPS Compound, 2016.

The statistics above reveals and supports the household data that, home visiting and community sensitization programmes were carried out on weekly and monthly basis. Five volunteers responded that home visiting was carried out weekly before the introduction of NHIS and monthly after the introduction. Whereas three and four volunteers also 
responded that community sensitization programmes were carried out on monthly basis before and after the introduction of NHIS.

The volunteers shared their experiences with the CHPS practice before and after the introduction of NHIS by revealing that $\mathrm{CHOs}$ were embarking on their home visiting and other preventive health programmes frequently. The volunteers further added that, due to user charges people who get sick, especially children were sometimes not taken care of. The CHVs concluded that the education by CHOs on prevention of diseases is of great benefit to the communities.

With the introduction of NHIS however, the educational programmes by the CHOs enabled most people to subscribe to the scheme. This has resulted in increased work load on the CHOs due to the rising OPD attendance.

\subsection{Response of Community Health Management Committees (CHMCs) on Their Roles}

The Community Health Management committee is a group of community men and women that serve as the major structures upon which CHPS rests. It usually comprises of abled men and women selected from the communities within the CHPS zone. The committees are put in place to ensure the proper functioning of CHPS in the Vieri zone by seeking the well-being of the CHOs and monitoring the activities of the CHVs to ensure the CHPS sustainability. They serve as a link between the $\mathrm{CHO}$ and the CHVs. The Vieri CHPS zone currently has 13 committee members. There are ten for Vieri, two for Gorziri and one for Lomwana. Out of a total number of thirteen committee members, five were interviewed thus three from Vieri and one each from Gorziri and Lomwana. The table below shows the sex composition of the community health management committees.

Table 6. Composition of CHMC.

\begin{tabular}{llll}
\hline Community & Number of males & Number of females & Total \\
\hline Vieri & 10 & 0 & 10 \\
Goziri & 1 & 1 & 2 \\
Lomwana & 1 & 0 & 1 \\
Total & 12 & 1 & 13 \\
\hline
\end{tabular}

Field survey, 2016.

From the table above, it can be deduced that the formation meets the average number of five members as stipulated by the CHPS policy. However, it contradicts the requirement that, the membership should not be the preserve of only men but should include women leaders and if possible with equal representation $(\mathrm{MOH}, 1999)$. Vieri community which has the majority of the membership has all it members as males. This implies that the women do not have a say in the health decision making process in the community unlike Gorziri and Lomwana whose membership are gender sensitive.

\subsubsection{Roles of Community Health Management Committees (CHMCs)}

Interviews held with $\mathrm{CHMCs}$ revealed a number of roles they perform with regards to CHPS. To clearly identify the lapses in their roles performed, a comparison is made with CHPS policy roles and the roles specified at the CHPS compound.

Policy Roles

- Settlement of disputes concerning the work of the CHVs.

- Organizing communal activities in support of the programmes.

- Advocating community health and family planning activities.

- Financial management of medical accounts.

- Managing CHVs stock of drugs and family planning materials.

- Supervising bicycle maintenance for community health volunteers.

CHPS compound specific roles

- Serves as liaison between community and health authority

- Mobilize community for communal activities on health issues.

- Advocate community health and family planning activities.

- Settling disputes arising from health issues.

- Supervise the work of the community health volunteer.

- Maintenance of logistics at the CHPS compound and with the CHV.

- Managing volunteers stock of drugs.

Community Health Management Committee (CHMC) responses to their roles

- Dissemination of information to the community when the need arises

- Settling of disputes between community members and the CHOs

- Working hand in hand with the CHOs

- Ensure the safety of the CHOs (e.g. organizing women to fetch water for the $\mathrm{CHO}$ ) and their accommodation

- Monitor the work of the volunteers

- Keeping the CHO's compound clean

A comparison of the three categories of roles above clearly shows that the committees works in line with their mandatory roles. This implies that the committees are really beneficial to the health system of the community as far as CHPS is concerned. However, it is faced with some challenges

The committee members explained that there is difficulty when it comes to pooling of resources together. Though the monies contributed are meant for the health care of the entire community, it is very difficult in raising such monies.

The committee members shared their views with regards to no support such as motivational packages received from the District health management team and the sub-district health management team. The committee does not receive any financial support from the authorities mentioned above.

Upon interviews, one of the committee members brought to the researchers' note that, there is lack of transparency in financial dealings. This he said is due to the fact that monies contributed for the running of health activities by 
committee members are not accounted for by the heads of committee.

\subsubsection{CHMCs Experience with the CHPS Practice}

The committee members reveal their thoughts with regards to the activities of the CHOs before and after the introduction of NHIS as illustrated in the table 7.

Table 7. Response of CHMCs to home visits and community sensitization.

\begin{tabular}{lllll}
\hline \multirow{2}{*}{ Interval } & \multicolumn{2}{l}{ Home visiting } & \multicolumn{2}{l}{ Community sensitization } \\
\cline { 2 - 5 } & Before & After & Before & After \\
\hline Weekly & 3 & 1 & 0 & 0 \\
Fortnight & 2 & 4 & 2 & 1 \\
Monthly & 0 & 0 & 3 & 4 \\
\hline
\end{tabular}

Field survey, 2016.

The above reveals that before the introduction of NHIS, home visits were carried out frequently as compared to after the introduction of NHIS. Also, community sensitization programmes were carried out on monthly basis before and after the introduction of NHIS.

The CHMCs shared their experiences with CHPS practice before and after the introduction of NHIS. The members revealed that, when CHPS was not in existence there were issues of infant and maternal mortality but with the establishment of CHPS in the area, these deaths have declined though they could not give the statistics on the deaths. They further added that clean up campaigns that were organized by the CHOs and the volunteers were of immense importance to them due to draining of stagnant waters to help prevent malaria.

Whiles some added that, NHIS subscription by has made it possible for most people to be able to access health care resulting in increasing attendance at the facility hence, limiting the activities to be carried out by the CHOs. Others seem not to have any idea about the effect NHIS is posing on the CHPS initiative.

\subsection{Subscription to NHIS in the Vieri CHPS Zone}

As a result of the objectives of the research in identifying the effect of NHIS on CHPS practice, the number of households subscribed to the NHIS within the CHOS zone is as follows.

Table 8. Subscription to NHIS in the Vieri CHPS zone.

\begin{tabular}{lllll}
\hline Community & Subscribed & Percentage & Not subscribed & Percentage \\
\hline CHPS zone & 139 & 84.2 & 26 & 15.8 \\
Vieri & 116 & 85.9 & 19 & 14.1 \\
Gorziri & 18 & 78.3 & 5 & 21.7 \\
Lomwana & 5 & 71.4 & 2 & 28.6 \\
\hline
\end{tabular}

From the above table, majority of households in the zone are subscribed to the NHIS which makes them to easily access health care whenever the need arises. The percentage of subscribers within Vieri is higher than the percentage for the entire zone which implies that Vieri community is better off in accessing health care. Also, in spite of the prevailing poverty in Upper West Region and the Wa West District, majority of households in this zone thus under the Lassie sub-district have made all possible to subscribe to the scheme. This is no doubt as Upper West Region is the Region with the highest percentage of subscribers in the country, out of 10 regions (Gajate-Garido and Owusua, 2013). The percentage of subscribers in this region is $60.7 \%$ with valid cards and $7.8 \%$ without valid cards and $31.5 \%$ not registered. Though the Vieri zone has higher subscription rate as compared to the region, the question arises whether all have valid cards (Gajate-Garido and Owusua, 2013).

\subsection{Place of Accessing Health Care by Households in the Vieri Zone}

The figure below illustrates the patronage of health facilities in accessing health care by households within the zone.

Majority of households' access health care in the facility closest to them which is the Vieri CHPS compound. About 93.9\% of households in the entire CHPS zone access health care at the CHPS compound with only $6.1 \%$ who go to other places. The other places include Lassie, Wechiau (about $36 \mathrm{~km}$ from the zone) and the Upper West Regional hospital in Wa thus 14 miles away from them. The households who fall within the others category explain that they go to these places sometimes because upon reaching the CHPS compound, too much people are there and therefore feel they would not receive the needed attention from the CHOs. Also, they added that there is sometimes shortage of drugs at the CHPS facility which compels them to go to other facilities. Hence, in order not to be waiting whiles the sickness is getting serious, they proceed to the other places. Among those who access health care at the CHPS compound also, some go to these other places upon referral by the CHOs due to complicated issues or shortage of drugs.

The above underscores the fact that, households perceive the CHPS compound as a clinic and for that matter see the work of the nurse as a "clinical health nurse" rather than a "preventive nurse". Households therefore patronize the facility to seek healthcare as soon as they fall sick in order to compensate the cost paid by them to their insurers. One household head who was interviewed on how frequent he access health care said, "because me and my households paid money to the scheme to get insured, we will also make sure that we also benefit by visiting the CHPS compound even with the slightest headache in order to compensate our loss".

The above explanations contradict the view of the $\mathrm{MOH}$ which says "the major role of the nurse is house to house health education and preventive health care and not sedentary clinic activity at home" (MOH, 2000: 24).

\subsection{Access to Health Care Before the Introduction of NHIS}

Households were interviewed about their ability to access health at the CHPS compound before NHIS was introduced. 
Table 9. Households ability to access health care before NHIS.

\begin{tabular}{lllll}
\hline Community & Yes & Percentage & No & Percentage \\
\hline Entire CHPS zone & 96 & 58.2 & 64 & 38.8 \\
Vieri & 75 & 55.6 & 56 & 40.7 \\
Gorziri & 14 & 60.1 & 8 & 34.8 \\
Lomwana & 7 & 100 & 0 & 0 \\
\hline
\end{tabular}

The above illustrates that majority of households were able to access health care even when NHIS was not introduced. This is in view of the fact that households understand how important it is to be healthy and be able to carry out their normal livelihood. Further explanations by the households however reveal that they do not find it easy to raise such monies. They had to either borrow from other family members, sell out some of their animals and food stuffs left for household consumption. Therefore, they were not going the as frequent as now but rather do selective attendance by going to the facility when the sicknesses were complicated and could not be managed by the households. Where these could be managed however, they resort use of herbal medicine by boiling and self-medication. About 90 households representing $56.3 \%$ paid user charges whiles 32 households representing $19.4 \%$ could not access due to user charges and six households representing $4.2 \%$ accessed by paying user charges and using herbal medicine whiles 16 households representing 9.7\% resorted to herbal medicine usage. About 15 households also representing $9.1 \%$ also said they hardly fall sick whiles one (1) household $(0.6 \%)$ said they depended on divine healing. The frequency of households accessing health care at the CHPS compound before and after the introduction of NHIS is illustrated in the figure below.

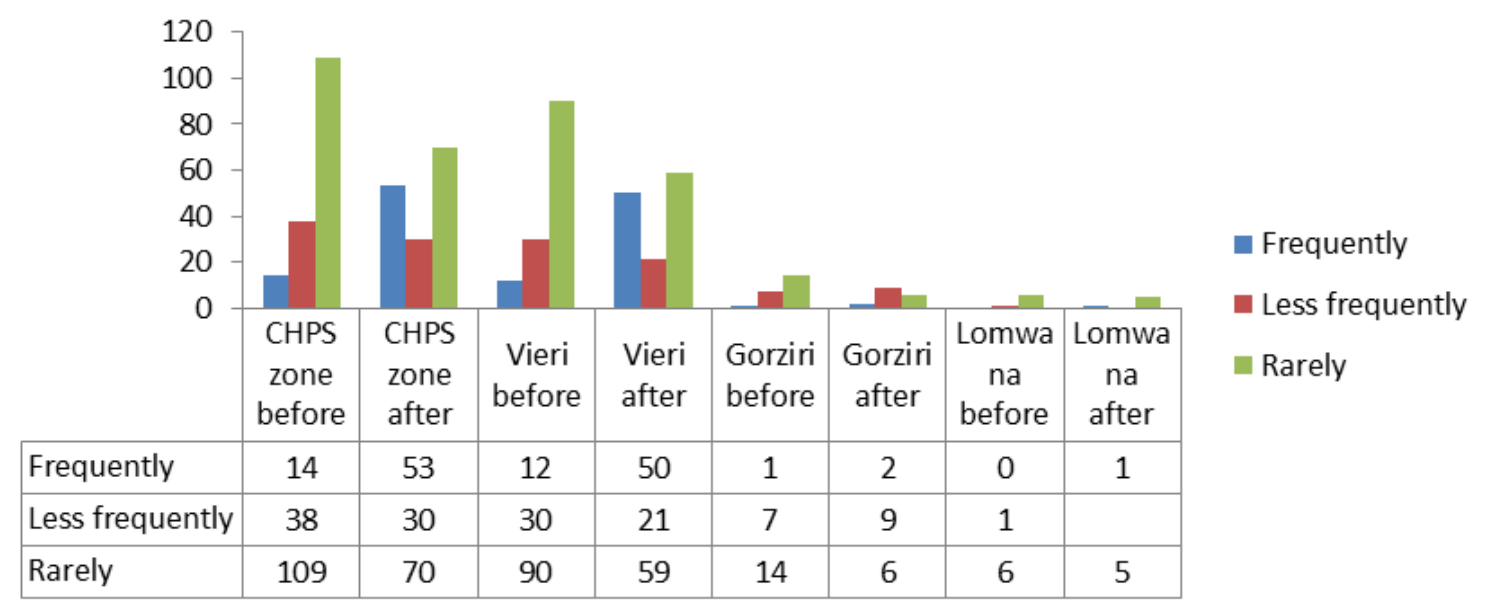

Figure 4. Frequency of health care access at the Vieri CHPS compound.

In the above figure, the responses to frequently imply that the households access health care every week to two whereas less frequently imply accessing health care every month to two and rarely implying accessing health care every three months and above.

In the entire CHPS zone the households that rarely visited the facility before NHIS was introduced was about $62.2 \%$ which was simply due to the fact that user charges constrained their ability to access health care frequently and for that matter resorting to self-medication and use of herbal medicine whiles reporting complicated issues at the facility. After the introduction of NHIS however, the households that accessed health care frequently more than doubled (about $278.6 \%$ increment) from 14 households to 53 thus from. The households that rarely access health care reduce by $35.8 \%$ in favour of those who accessed frequently. This could be ascribed to the ease in accessing health care now with NHIS. This will also imply a corresponding reduction in issues of self-medication.

\subsection{Type of Cases Allowed to Be Handled by a CHPS Facility and Cases Actually Reported at the Vieri CHPS Compound}

According to the Ministry of Health (2005: 25), the curative services required to be handled by a CHPS facility (Curative and Rehabilitative-Management of minor ailments and referrals) are treatment of uncomplicated malaria and fevers, treatment of simple cough and Urinary and Respiratory Tract Infection (URTIs), treatment of simple diarrhoea, first aid for burns, cuts, toxic inhalation and consumption (Home accidents), blood pressure monitoring, first aid for spontaneous delivery.

The cases that were actually reported and taken care of by the CHOs at the CHPS compound since 2001 were simple malaria, Acute Respiratory Tract Infection (ARTI), uncomplicated eye and ear infections, skin infections, RTA, wound dressing and Convulsion

A comparison of the above clearly shows that apart from convulsion, which has not been explicitly mentioned in the $\mathrm{MOH}$ policy document, the CHPS compound is working in line with the mandate provided by the CHPS policy. This implies that cases beyond their control are referred to the next level facilities at Lassie, Wechiau or Wa.

\subsection{Effect of Accessibility Trend on the Infrastructure and Services Delivered}

Out of the total respondents of 165 households for the entire CHPS zone, 140 households representing 84.8\% 
revealed that there has been crowding at the CHPS compound due to the greater number of people that visit the facility day in day out hence, the attendance at the Vieri CHPS compound has had effect on the facility and the services delivered. The effects on the facility include inadequate space for keeping record folders and other logistics. The CHOs added that due to increased attendance, they did not have adequate space to keep some records which needed to be disposed of. This is one of the issues that constrained the ability of the researchers to do a before and after analysis of the home visiting and community sensitization since these records could not be traced.

The consequence of the rise in the attendance poses on the CHOs is that, it has made the work of the CHOs stressful as 128 households representing $77.6 \%$ reveals this. Though stressful, it varies from day to day and very high on market days. Also, it varies on seasonal basis due to certain environmental factors. Due to the above, the CHOs hardly get time to carry out their personal activities.

These further go to affect the services delivered as 119 households representing $72.1 \%$ said the services delivered there upon the introduction of NHIS is poor. Respondents complain of longer waiting time and preferential treatment given to patients.

Moreover, there are instances of shortage of drugs which compels patients to go to Lassie and other health facilities around them. The extra cost incurred as a result of patients moving to the other facilities might compel them to resort to self-medication.

The increased attendance at the facility has led to the increase in the cases reported more than the ability of the facility to handle. Also, some of the cases common in the area that is reported at the facility mostly required referral to the next level of facility, coupled with factors such as adequate curative health staff led to the transformation of the CHPS compound into a health centre. However, the CHPS facility will be maintained as urban CHPS to ensure that it does not fade out in the area in order to enable the CHOs to continue rendering their preventive health care services.

\section{Conclusion}

The Ministry of Health in collaboration with the Ghana Health Service has provided various means by which the gaps between the rich and the poor in accessing health care were bridged. It is clear and evident that both CHPS and NHIS have all come to stay in the health care system of Ghana. CHPS has come in to reach the neglected in our rural areas in order to bridge the gap in access to health care between those reached by health facilities and those not reached. The NHIS also came in to ensure the financial barrier in access to health care. This has also enabled the poor who could not afford to pay user charges at the health facilities. Both these two are parts of Ghana's health system to ensure the provision of preventive and curative packages of primary health care and hence provide health for all citizenry of this country. In effort to make one effective, the other must not be relegated to the background because they both have important roles to play in the health care delivery system of the country.

Therefore, mechanisms should rather be put in place in order to ensure that both render their services respectively in a harmonious manner such that the function of on does not hinder the ability of the other in rendering its service. These are seen in the recommendations below.

\section{References}

[1] Apetorgbor, V. E. A. (2008). Review of the Implementation Process of Community-based Health Planning and Services, unpublished MSc. Public Health Thesis, Vrije Universiteit Amsterdam, The Netherlands.

[2] Cutler, D. M. and Zeckhauser, R. (2003). Extending the Theory to Meet the Practice of Insurance. Harvard University and NBER. Retrieved from,

http://www.scholar.havard.edu/cutler/publications/extendingtheory-meet-practice-insurance.

[3] Dekker, M. Community-Based Health Insurance in Ethiopia, retrieved June $12^{\text {th }} 2013$, from http://www.ascleiden.nl/?q=research/projects.

[4] Faden, L., Vialle-Valentin. C. Ross-Degnan, D. and Wagner, A., (2011). Review series on pharmaceutical pricing policies and interventions: The role of Health Insurance in the costeffective use of medicine (working paper 2), WHO/HAI Project on Medicine Prices and Availability. Retrieved from http://www.haiweb.org/medicineprices/197073376/competitio n final May 2011.

[5] Gajate-Garrido, G and Owusua (2013). The National Health Insurance Scheme in Ghana: Implementation challenges and proposed solutions. IFPRI Discussion Paper 1309. Washington, D. C.: International Food Policy Research Institute (IFPRI).

[6] Retrieved from http://www.ifpri.org/publication/nationalhealth-insurance-scheme-ghana.

[7] Ghana Health Service, (2005). Policy Document No. 20, Community-based Health Planning and Services (CHPS) Operational Policy, Accra.

[8] Ghana Millennium Development Goals, (April 2010). 2008 Ghana Millennium Development Goals Report.

[9] Heitman, E. and McKieran, L. C. (2003). Community-Based Practice and Research (module 4): Collaboration and Sharing Power. Retrieved from http://www.asph.org/userfiles/module4.pdf.

[10] Ministry of Health (1999). Community-based Health Planning and Services Handbook.

[11] Ministry of Health (2000). Community-based Health Planning and Services (CHPS) Implementation Guide.

[12] Ministry of Health (2009). A report of the Annual Health Sector Review, In-depth Review of the Community-based Health Planning Services (CHPS) Programme, Accra.

[13] Ministry of Health, (2012). Half Year Report, January-June, Accra. 
[14] Ministry of Health/Ghana Health Service, (2002). Technical Report No. 32, CHPS Lead District Readiness Assessment Ghana.

[15] Nang-Beifubah, A. (2010). GHS/JICA Disseminate Final Report on CHPS Project, retrieved from http://www.ghanaweb.com/home/news/health/article/175405.

[16] NHIA (2010). Annual Reports. National Health Insurance Scheme, Ghana.

[17] World Health Organization (1978). Primary Health Care.
Report of the international conference on primary health care. Alma-Ata, USSR: WHO Geneva 1978.

[18] World Health Organization (WHO, 2004). Centre for Health Development, Ageing and Health Technical Report (Volume 5): A glossary of terms for community health care and services for older persons. Retrieved from www.who.nit/. ahp_vol.5.

[19] World Health Organization (WHO, 2008). The World Health Report 2008, Primary Health Care-Now More than Ever, Geneva. 